\title{
Percepção socioambiental em relação ao avanço do mar na Praia de Icaraí, Caucaia, Ceará, Brasil
}

\section{Maurício Rodrigues de Araújo ${ }^{1}$ e Ivan Jeferson Sampaio $\operatorname{Diogo}^{2}$}

${ }^{1}$ Faculdade Terra Nordeste. Rua Coronel Correia, 1119. Soledade. Caucaia-CE, Brasil (CEP 61600-000).

${ }^{2}$ Instituto Federal de Educação, Ciência e Tecnologia da Paraíba. Campus João Pessoa. Av. Primeiro de Maio, 720. Jaguaribe. João Pessoa-PB, Brasil (CEP 58015905).E-mail: ivan.diogo@ifpb.edu.br.

Resumo. As faixas de praia funcionam como depósitos de sedimentos, que são constituídos por areias e cascalhos. 0 objetivo desse trabalho foi analisar a percepção socioambiental em relação ao avanço do mar na Praia de Icaraí, Caucaia, Ceará. A pesquisa teve abordagem quantitativa, de caráter descritivo e cunho bibliográfico. A população da pesquisa é formada por usuários, residentes e não residentes, da Praia de Icaraí. 0 estudo foi realizado no mês de junho de 2019, quando foi coletada uma amostra aleatória de 40 pessoas, abrangendo os vários segmentos da população. 0 público que frequenta a Praia de Icaraí são moradores locais (50\%), seguidos por frequentadores (37,5\%) e, por fim, os comerciantes $(12,5 \%)$. Como atrativos e atividades praticadas, 42,5 dos entrevistados afirmaram que utilizam a praia para a prática de esportes como surf, $25 \%$ utilizam a praia para atividades de lazer, $20 \%$ afirmaram que não existem mais atrativos, e $12,5 \%$ para trabalhar. Com relação ao risco de avanço do mar, mar e erosão costeira de Icaraí, 75\% dos entrevistados afirmaram que é muito alto, e $25 \%$ alto. Assim, os principais problemas ambientais que vem ocorrendo na praia de Icaraí são o lixo, a destruição de dunas da praia, limpeza da praia, coleta seletiva; além de problemas sociais como violência, destruição de barracas. É necessária a conjugação de mudanças culturais e transformações institucionais para estimular os cidadãos a participarem na produção de suas condições de existência e alterarem seus projetos de vida, de modo que possam preservar o meio ambiente para futuras gerações.

Palavras-chave: Erosão costeira; Riscos ambientais; Problemas sociais; Preservação ambiental.

Abstract. Socio-environmental perception in relation to the sea advance at Icaraí Beach, Caucaia, Ceará, Brazil. The beach strips act as sediment deposits, which consist of sands and gravel. The objective of this work was to analyze the social and environmental perception regarding the advancement of the sea
Recebido $16 / 04 / 2020$

Aceito

$26 / 08 / 2020$

Disponível on line

$27 / 08 / 2020$

Publicado

$31 / 08 / 2020$

Acesso aberto

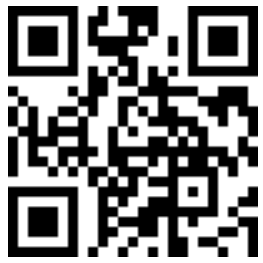

ORCID

() 0000-0003-0140-4106 Maurício Rodrigues de Araújo

(D) 0000-0002-5440-9851 Ivan Jeferson Sampaio Diogo

ISSN 2359-1412/RBGAS-2019-0109/2020/7/16/27/873

Rev. Bras. Gest. Amb. Sustent.

http://revista.ecogestaobrasil.net 
in Icaraí Beach, Caucaia, Ceará. The research had a quantitative approach, descriptive and bibliographic nature. The research population is made up of resident and non-resident users from Praia do Icaraí. The study was conducted in June 2019, when a random sample of 40 people was collected, covering the various segments of the population. The public that frequents the beach of Icaraí are local residents (50\%), followed by regulars (37.5\%) and, finally, merchants (12.5\%). As attractions and activities practiced, $42.5 \%$ of respondents said they use the beach for sports such as surfing, $25 \%$ use the beach for leisure activities, $20 \%$ said that there are no more attractive, and $12.5 \%$ to work. With regard to the risk of sea advance, sea and coastal erosion of Icaraí, $75 \%$ of respondents said it is very high, and $25 \%$ high. Thus, the main environmental problems that have been occurring on Icaraí beach are the amount of garbage, beach dune destruction, beach cleaning, selective collection; besides of social problems such as violence, the destruction of tents. It is necessary to combine cultural changes and institutional transformations to encourage citizens to participate in the production of their living conditions and to change their life projects so that they can preserve the environment for future generations.

Keywords: Coastal erosion; Environmental risks; Social problems; Environmental preservation.

\section{Introdução}

As faixas de praia funcionam como depósitos de sedimentos, que são constituídos por areias e cascalhos, que conectam corpos hídricos de água doce e água salgada, como rios, lagos, mares ou oceanos. As praias possuem importância ambiental significativa por serem locais de desova de animais, por abrigarem uma diversidade de espécies vegetais e animais, além de serem sistemas dinâmicos.

Inclui-se aí a importância social e econômica singular, visto que abriga vilas de comunidades tradicionais e abastecem a população no tocante às atividades de pesca, esportes, cultura, turismo e recreação (Coriolano e Silva, 2005; Ergin et al., 2006). Para as populações que vivem nestes ambientes, o avanço do mar é uma das principais ameaças, resultando em erosão costeira, que causa grandes impactos destrutivos (MacLeod et al., 2002; Martins et al., 2016).

A erosão da faixa de praia é resultado do desequilíbrio no aporte de sedimentos, ou seja, quando há mais quantidade de material erodido do que depositado. 0 litoral do estado do Ceará está propenso ao avanço do mar, o qual destrói casas, barracas, hotéis e estruturas de defesas, como bagwalls, prejudicando potencial turístico litorâneo, comunidades nativas e polos de lazer (Farias e Maia, 2010).

Os registros de destruição são resultados de uma ação combinada de agentes naturais, como ondas, marés, ventos, configurações da costa e agentes antrópicos, ou seja, as intervenções do homem em áreas de aporte sedimentar como dunas e cursos hídricos (MacLeod et al., 2002).

Desta forma, a análise da percepção ambiental se apresenta como uma ferramenta importante, por ressaltar o ponto de vista daqueles que mais participam da realidade local. Denota-se a importância de compreender os apontamentos, visualizações e preferências dos usuários para o gerenciamento costeiro. Além disso, a percepção da comunidade local 
é de extrema relevância na busca de uma sadia qualidade de vida e desenvolvimento sustentável para as populações locais (Marin et al., 2009; Souza, 2009; Fernandes e Sansolo, 2013).

A intensificação dos processos erosivos na zona costeira de Caucaia, no Estado do Ceará, reduziu aproximadamente $300 \mathrm{~m}$ de faixa de praia nas Praias de Icaraí, Pacheco e Iparana, com recuo de linha de costa a uma taxa de $-3.3 \mathrm{~m} / \mathrm{ano}$, caracterizando-a como área de elevado grau de vulnerabilidade à erosão marinha (Farias e Maia, 2010). Como o avanço do mar na zona costeira de Caucaia, tem um impacto muito negativo na economia, no meio ambiente e na população local, o estudo da percepção ambiental é de extrema importância para auxiliar na elaboração de ações que venham a adequar, manter, ou mesmo aprimorar a eficiência destas intervenções, minimizando os custos operacionais e os impactos sobre o meio ambiente.

Este trabalho teve como objetivo geral analisar a percepção socioambiental da população local em relação ao avanço do mar na Praia de Icaraí, no Município de Caucaia, Ceará. E como objetivos específicos foram (a) delimitar o perfil social dos usuários da Praia do Icaraí e os principais atrativos para sua utilização, (b) discutir os principais problemas socioambientais decorridos do avanço do mar na Praia do Icaraí, (c) investigar fatores responsáveis e medidas mitigadoras do avanço do mar em Caucaia, bem como (d) quantificar o grau de satisfação da população em relação às atividades realizadas até o momento.

\section{Material e métodos}

\section{Área de estudo}

O litoral de Caucaia, Nordeste do Brasil, está inserido na macrorregião pertencente à Região Metropolitana de Fortaleza, distando cerca de $20 \mathrm{~km}$ de Fortaleza, capital do estado (Figura 1). A zona costeira do município tem aproximadamente $25 \mathrm{~km}$ de extensão, sendo limitado pelo Rio Ceará, a leste, e pelo Porto do Pecém, a oeste, incluindo as praias de Iparana, Pacheco, Icaraí, Tabuba, Cumbuco e Cauípe.

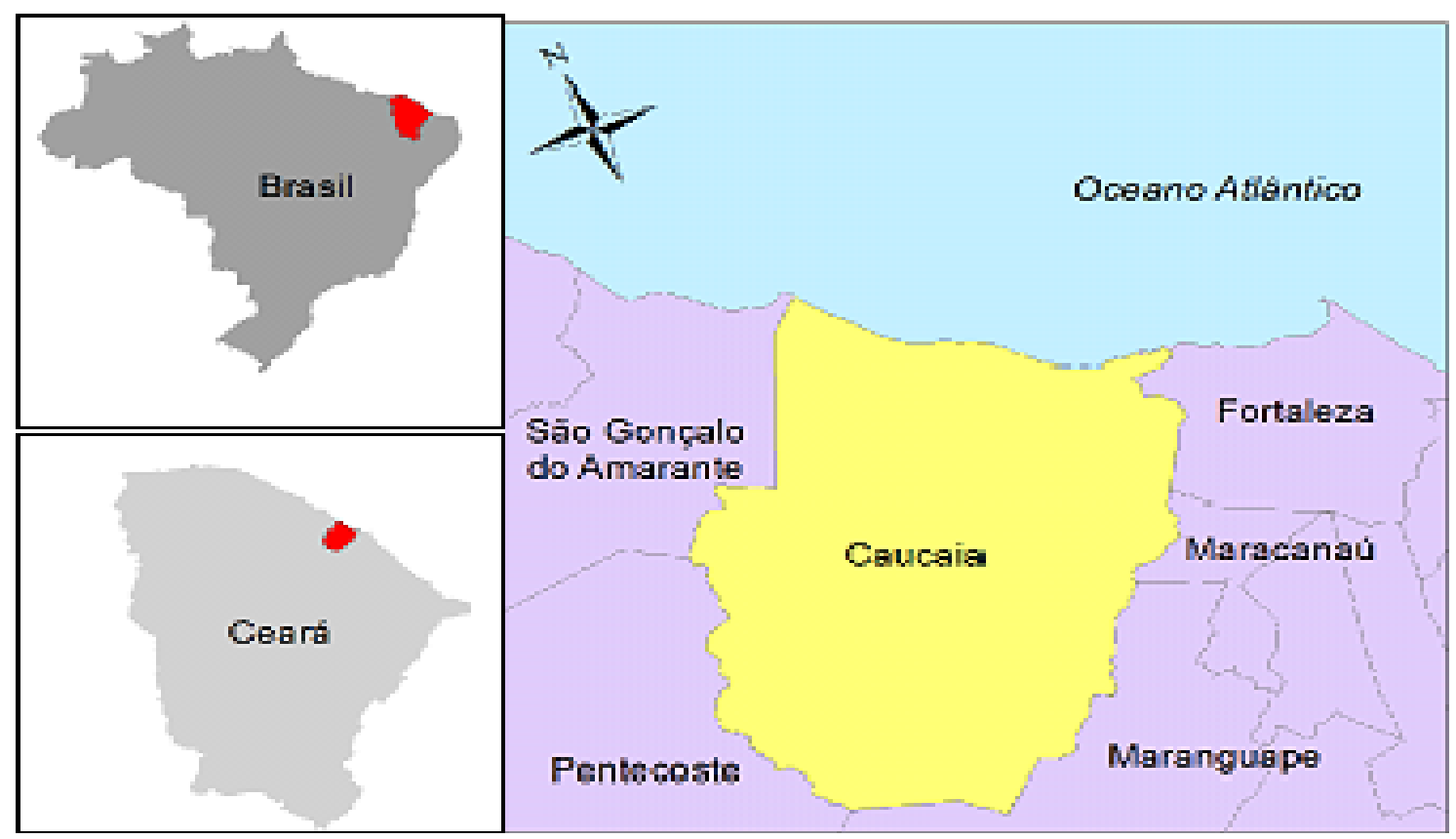

Figura 1. Localização do litoral do Município de Caucaia, Estado do Ceará, Brasil. 
A população fixa do Município de Caucaia é de aproximadamente 363.982 habitantes, aumentando muito nos períodos de férias com a chegada de turistas e veranistas (IBGE, 2014). Caucaia é o município mais visitado por turistas que ingressam ao Ceará via Fortaleza (mais de $17 \%$ do total), das dez praias mais visitadas do estado, duas estão localizadas no Município de Caucaia, a Praia de Cumbuco e a Praia de Icaraí (SETUR, 2012).

As praias do litoral do Município de Caucaia possuem uma posição estratégica por estar entre Fortaleza, que reúne a maior demanda turística do estado, e São Gonçalo do Amarante, município onde projetos de infraestrutura de elevados investimentos estão sendo implantados, tais como o Complexo Industrial Portuário do Pecém (CIPP), termoelétricas e siderúrgica. Destaca-se que, deste litoral, apenas Cumbuco e Cauípe ainda não apresentam problemas sérios de erosão costeira.

A Praia do Icaraí tem em torno de $4 \mathrm{~km}$ de linha de costa, dos quais a maioria está ocupada por infraestruturas urbanas. Possui uma faixa de praia arenosa com corpos de dunas, falésias de erosão marinha e rochas de praia (Paula et al., 2015). Esta praia está compreendida entre a desembocadura do Rio Barra Nova, a oeste, e a Praia de Pacheco, a leste (Figura 2).

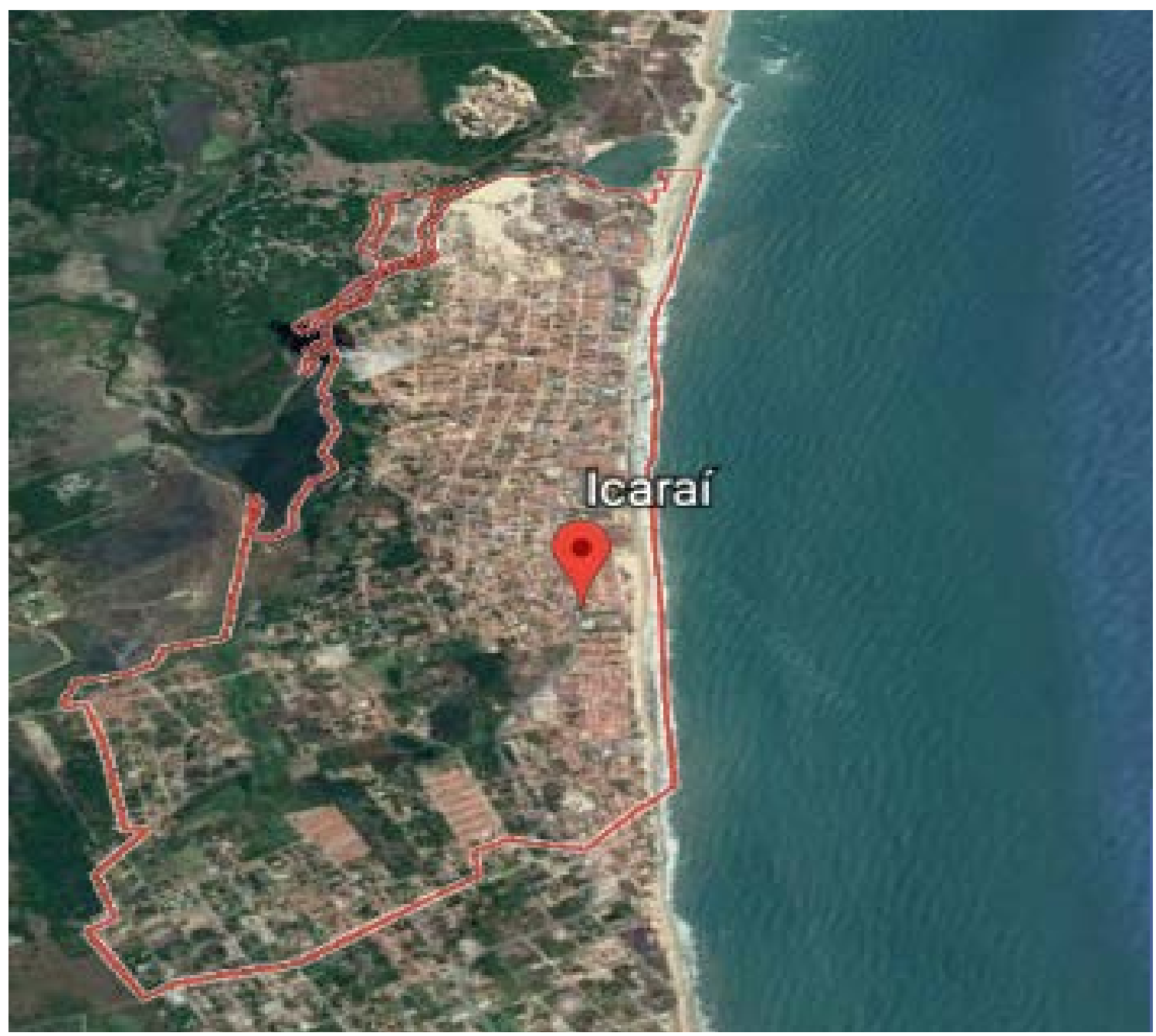

Figura 2. Localização da Praia do Icaraí, Município de Caucaia, Ceará. Fonte: Google Earth (2020). 


\section{Análise dos dados}

Para atingir o objetivo proposto neste estudo, realizou-se um estudo com abordagem quantitativa, de caráter descritivo e cunho bibliográfico. A pesquisa quantitativa é uma classificação do método científico que utiliza diferentes técnicas estatísticas para quantificar opiniões e informações para um determinado estudo (Gil, 2010). Ela é realizada para compreender e enfatizar o raciocínio lógico e todas as informações que se possam mensurar sobre as experiências humanas.

Neste tipo de pesquisa, os meios de coleta de dados são estruturados através de questionários de múltipla escolha, entrevistas individuais e outros recursos que tenham perguntas claras e objetivas. As técnicas empregadas no estudo de percepção ambiental consistem da combinação de três métodos básicos, observar, escutar e fazer perguntas (Fernandes e Sansolo, 2013).

Esta pesquisa foi realizada em duas etapas: levantamento preliminar de dados e aplicação de questionário. O levantamento preliminar de dados teve como finalidade descrever a dinâmica dos processos físicos, sociais e econômicos na Praia do Icaraí. Para isto, foram realizadas as seguintes técnicas de pesquisa: (a) revisão de literatura, (b) visita de campo para observação da dinâmica socioeconômica e ambiental da praia e (c) conversas informais com os usuários da localidade.

Estas informações serviram de base para a elaboração do questionário semiestruturado da pesquisa. 0 questionário é considerado um dos instrumentos mais utilizados na investigação social, sobretudo nos estudos de percepção da paisagem. A população da pesquisa é formada por usuários, residentes e não residentes, da Praia do Icaraí. O estudo foi realizado no mês de junho de 2019, quando foi coletada uma amostra aleatória de 40 pessoas, abrangendo os vários segmentos da população.

\section{Resultados e discussão}

Com o intuito de caracterizar o perfil dos entrevistados e frequentadores da praia do Icaraí, verificou-se que 55\% do público-alvo são do gênero masculino e $45 \%$ feminino. Em relação à faixa etária, há uma variação de 19 a 71 anos entre homens e de 18 a 56 anos entre mulheres, com concentração de $40 \%$ entre $25-40$ anos e 37,5\% entre $41-65$ anos (Figura 3). Em relação à escolaridade, $10 \%$ dos entrevistados tem ensino fundamental, $55 \%$ nível médio e $35 \%$ ensino superior.

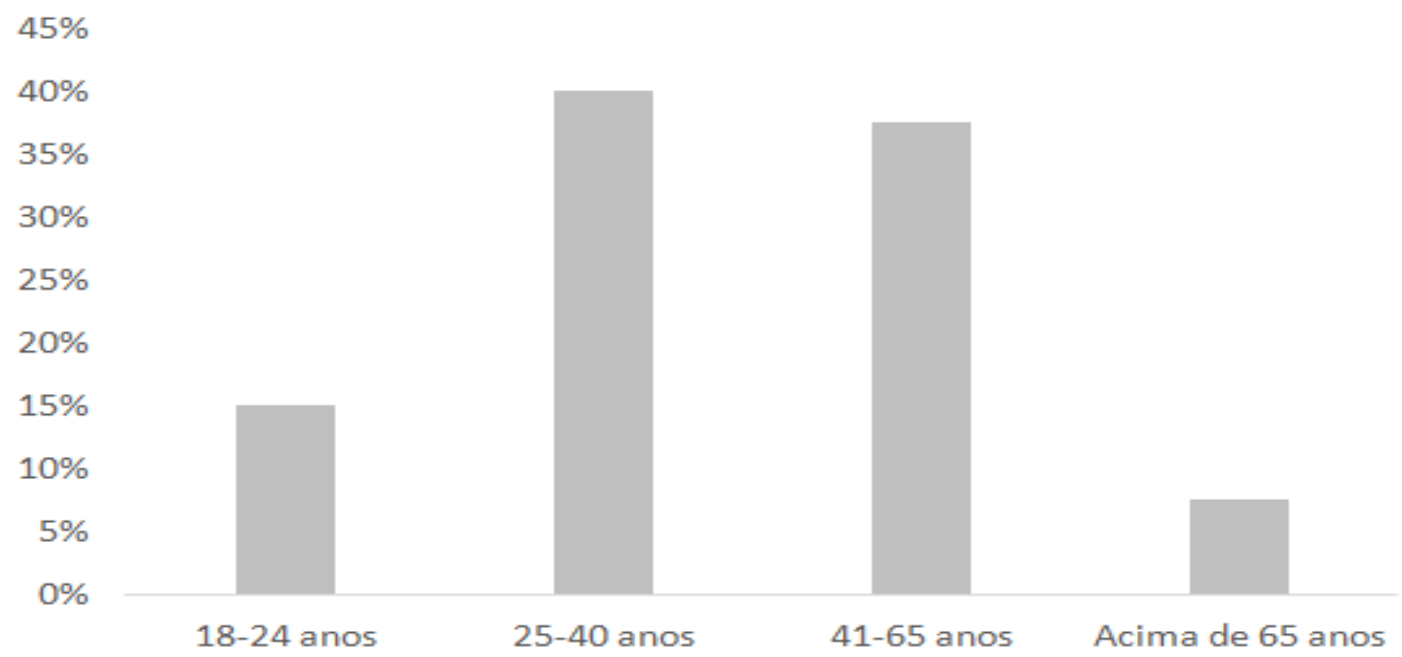

Figura 3. Faixa etária dos entrevistados na Praia do Icaraí/CE. 
Em relação ao público usuário da praia de Icaraí, a maioria dos entrevistados são moradores locais, seguidos por frequentadores não moradores e comerciantes (Figura 4). Os indicadores de familiaridade com a praia permitem avaliar o conhecimento dos usuários em relação às transformações ocorridas neste ambiente ao longo dos anos e os impactos destas transformações em suas experiências de praia (Medeiros et al., 2014).

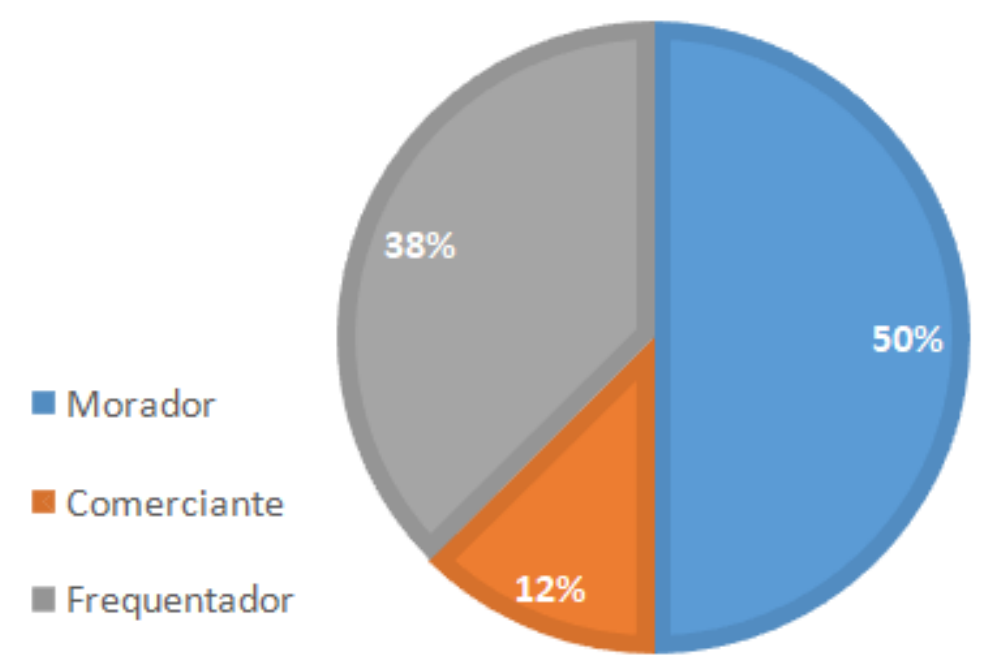

Figura 4. Perfil dos entrevistados de acordo com a categoria de usuário da praia.

A renda média da população é variável, no entanto a maior parte dos entrevistados ganha de 1 a 2 salários mínimo, seguido por 5 a 7 salários mínimos, 7 salários mínimos, 3 a 4 salários, e, por fim, 7,5\% não tem renda (Figura 5).

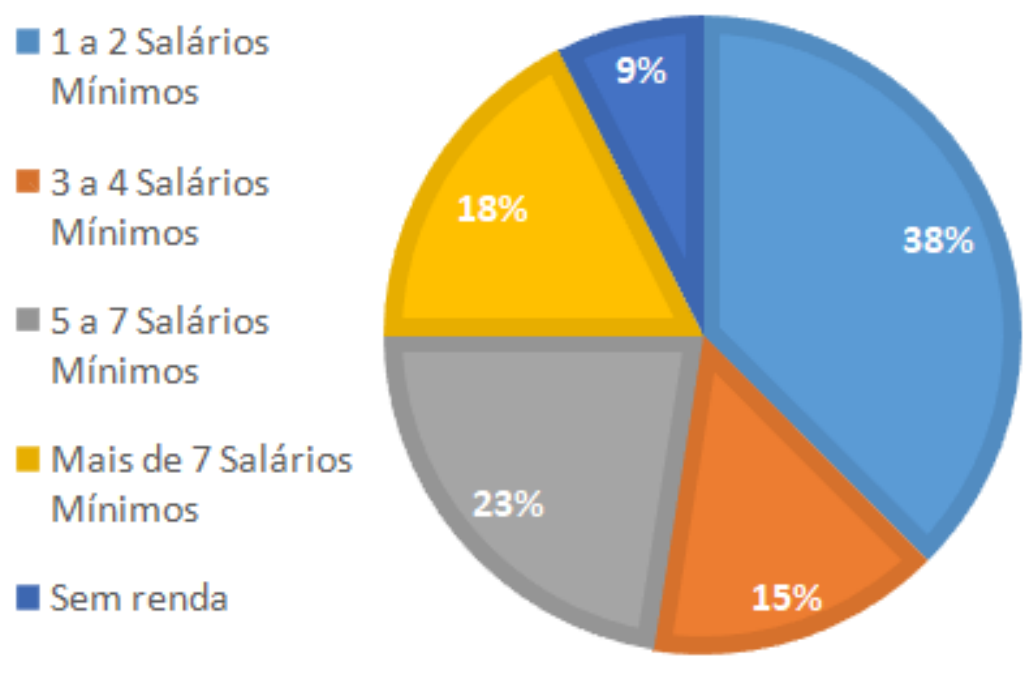

Figura 5. Renda média dos entrevistados. 
Os entrevistados frequentam a praia do Icaraí há muito tempo, variando entre 2 e 40 anos com uma preponderância daqueles que já possuem uma longa relação de familiaridade com a praia, 42,5\% começaram a frequentar de 2 a 10 anos atrás, enquanto $57,5 \%$ há mais de 10 anos. A maioria dos respondentes possui um tempo consideravelmente longo de visita à Praia do Icaraí ao ponto de estar familiarizada com as transformações decorrentes da erosão costeira na área. Dentro desse contexto, 42,5\% utilizam com o objetivo de moradia, seguidos por trabalho $(27,5 \%)$ e descanso $(30 \%)$.

Quanto aos principais atrativos e atividades praticadas na praia do Icaraí, a prática de esportes como surfe e kitesurfe representam a maioria das respostas, seguidas por atividades de lazer como banho e caminhadas, e atividades laborais como ambulantes e barraqueiros. É interessante notar que $20 \%$ dos respondentes afirmam que não existem mais atrativos na praia devido ao avanço do mar (Figura 6).

A Praia do Icaraí, historicamente, era uma praia famosa pelas suas barracas de praia, festas de carnavais e zona de surfe. Neste contexto, o avanço do mar no Icaraí vem sofrendo devido a uma série de fatores, dentre eles o impacto de obras de engenharia costeira em Fortaleza, que interrompeu o fluxo natural sedimentar que abastecia o litoral de Caucaia de acordo com a deriva litorânea e transporte eólico.

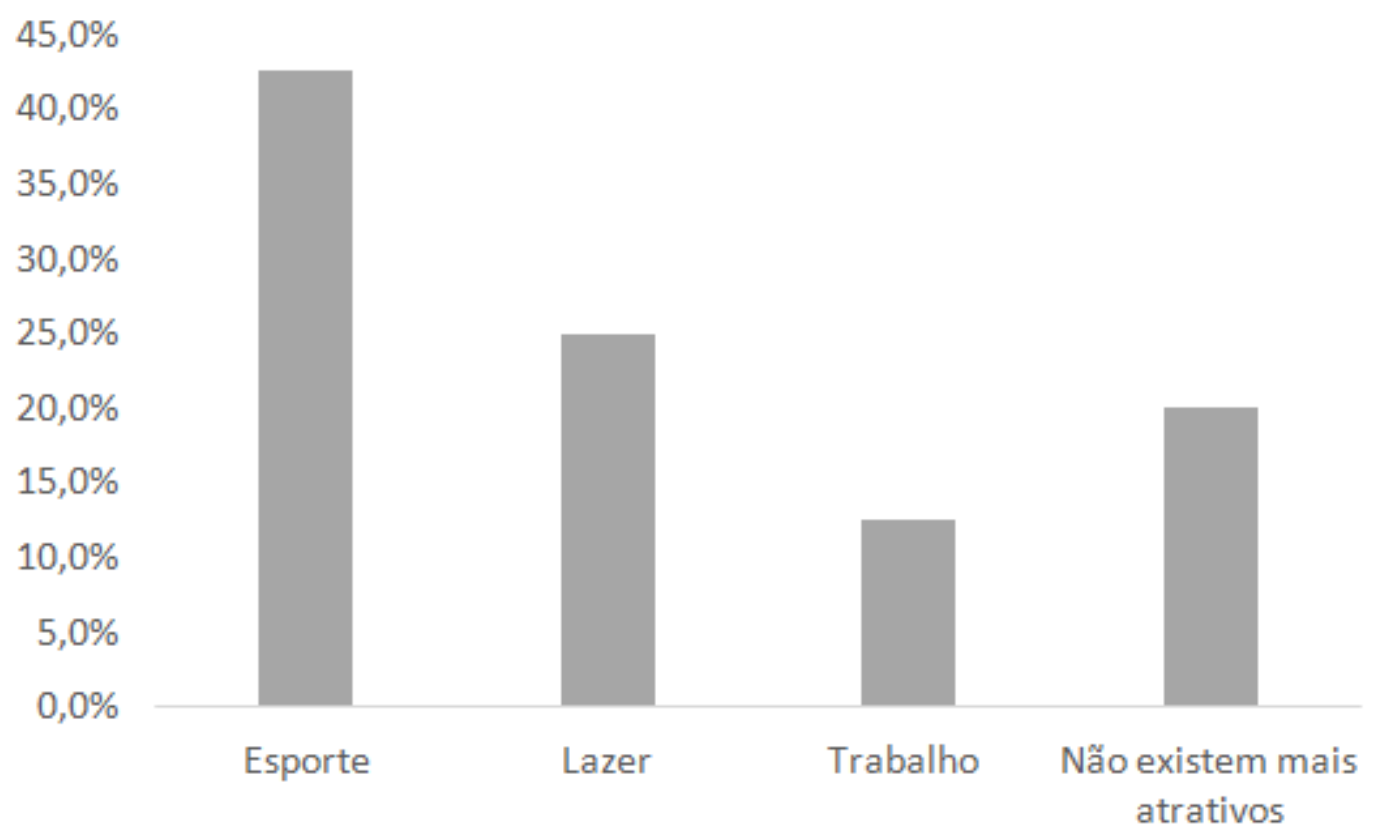

Figura 6. Principais atrativos e atividades praticadas na Praia do Icaraí.

0 avanço do mar foi reportado como um dos principais problemas ambientais que vêm ocorrendo na Praia do Icaraí. Os entrevistados também responderam que há acúmulo de lixo, a coleta ocorre de maneira desorganizada, e não existe coleta seletiva dos resíduos.

Outros apontam problemas socioeconômicos como insegurança, desvalorização imobiliária, corrupção, desemprego, corrupção, falta de áreas para esporte, cultura e lazer, descaso do poder público, ausência de urbanização, destruição de barracas e de estrutura para turismo. Por fim, apontam também problemas ambientais, como destruição das dunas da praia, limpeza da orla e erosão costeira (Figura 7). Esses problemas também foram encontrados por Medeiros et al. (2016). 
A ocupação da zona costeira no Estado do Ceará como em outras áreas do Brasil, tem sido feita, quase sempre, de forma desordenada, com o avanço das construções sobre áreas de dunas, comprometendo o caminhamento sedimentar alimentador das praias adjacentes, resultando no recuo gradativo da linha de praia e no avanço sistemático do regime de ondas sobre o berma, com a erosão da praia.

A erosão costeira tem causado efeitos negativos sociais e econômicos sobre a população local da Praia do Icaraí importante. Cerca de 20 barracas de praia foram destruídas, além de outras edificações públicas e privadas, contabilizando prejuízos materiais, sociais e econômicos, além de inestimáveis prejuízos ambientais. De acordo com Medeiros et al. (2016), a erosão costeira tem acarretado mudanças na paisagem de diversas praias, trazendo dificuldades para o desenvolvimento das atividades produtivas locais, como o turismo, a recreação e o comércio.
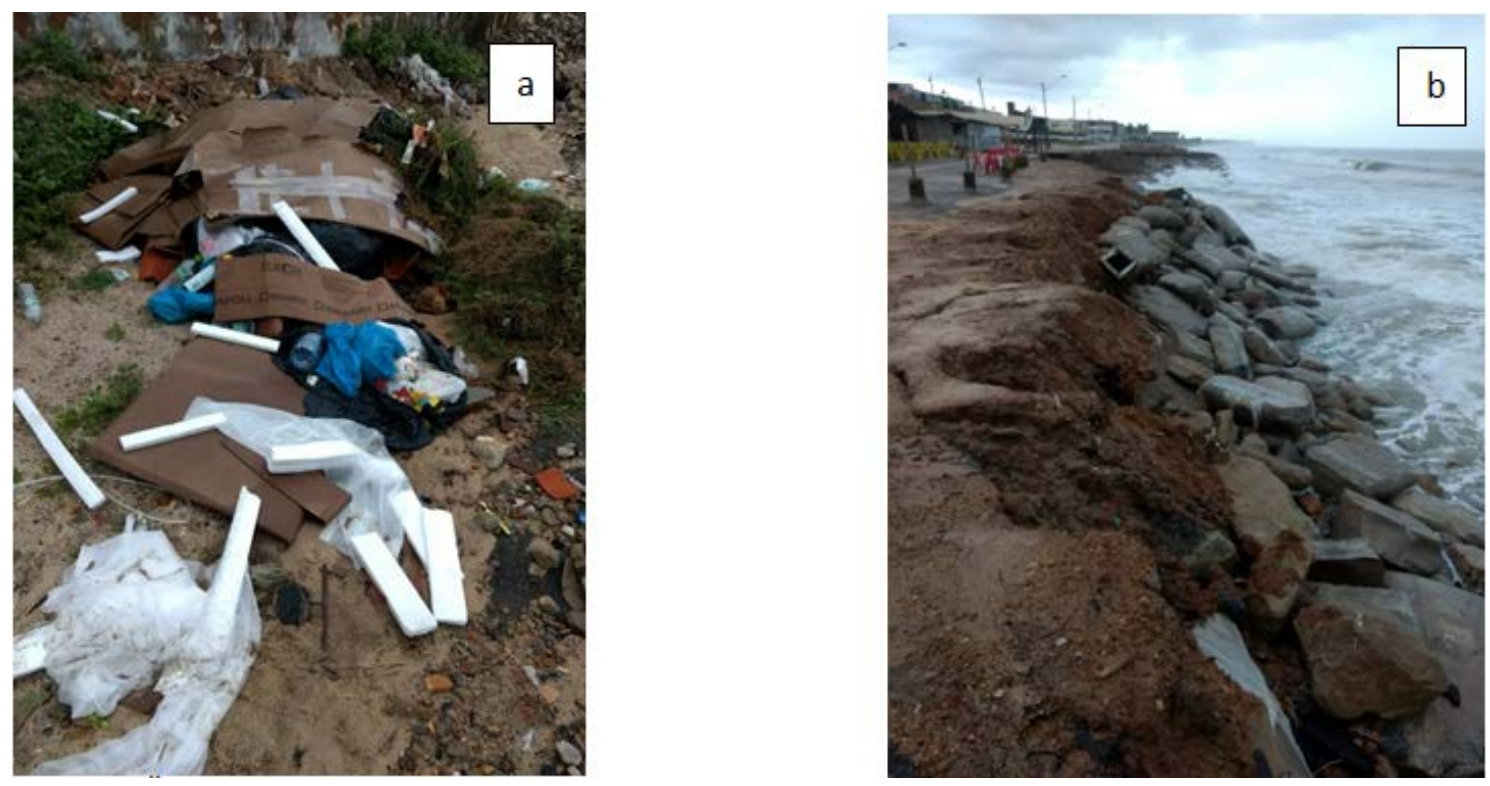

Figura 7. Problemas ambientais resultantes situados na faixa de praia da Praia do Icaraí. (a) Resíduos de uma barraca de praia; (b) Escombros de materiais destruídos pela erosão costeira.

É importante ressaltar que, como o problema da erosão resulta de um conflito entre o processo natural, o recuo da linha de costa, e a atividade humana, a solução do problema passa necessariamente pela questão do uso do solo na zona costeira. Tentativas de se estabilizar a posição da linha de costa através de obras de engenharia têm se mostrado ineficientes em controlar o fenômeno, e via da regra implicam na destruição da praia recreativa (Souza, 2011; Lins-de-Barros et al., 2016).

Quando perguntados sobre o risco de avanço do mar/erosão costeira do Icaraí, $100 \%$ da amostra considerou os problemas com riscos altos (25\%) e muito altos (75\%). Segundo Paula et al. (2015), estes riscos também foram avaliados pela Coordenadoria Municipal de Defesa Civil (COMDEC), que declarou tais impactos como situação de emergência com possibilidade de aumento da gravidade. 0 relatório constatou um elevado nível de destruição de edificações, infraestruturas e do próprio patrimônio natural, além do potencial de perigo para a população e ao patrimônio público e privado.

Os respondentes classificaram como fatores responsáveis pelo avanço do mar: o homem, a construção do Porto do Mucuripe, em Fortaleza, as construções de espigões na 
orla de Fortaleza, além de problemas ambientais de ordem global como destruição da camada de ozônio, aumento do nível dos oceanos e aquecimento global. Observa-se que $100 \%$ dos entrevistados relataram que o avanço do mar é causado por ação humana. A ação antrópica também é citada como a principal causa de processos erosivos em diversas partes do mundo (Souza, 2009).

No que tange ao lazer e turismo, todos os participantes concordam que o avanço do mar interfere no lazer e no turismo local. E que as obras de contenção realizada até agora não foram suficientes para solucionar o problema da comunidade e que estas obras de contenção prejudicam a paisagem da praia. 0 grau de satisfação com as atividades de contenção realizadas até o momento todos os entrevistados relataram grau de satisfação muito baixo com os trabalhos realizados de contenção até o presente momento.

A percepção dos entrevistados está de acordo com os resultados dos estudos realizados por Pinheiro et. al. (2005), Farias e Maia (2010) e Medeiros et al. (2016), que apontam que o campo de espigões na orla marítima da Fortaleza foi o responsável pela intensificação da erosão costeira na Praia do Icaraí. Segundo esses autores, os espigões retiveram parte dos sedimentos que abasteciam o litoral de Caucaia de acordo com o fluxo natural da deriva litorânea, transferindo gradualmente os processos erosivos da capital para as praias próximas, no sentido de leste para oeste, ou seja, de Fortaleza para Caucaia.

Em meados de 1990, o intenso processo erosivo do mar causou um recuo da linha de praias de Caucaia em torno de $-1 \mathrm{~m} /$ ano. A partir de 2004, esse fenômeno aumentou na Praia do Icaraí com um recuo da linha de costa de até -3,3m/ano (Farias e Maia, 2010). Devido a este fato, edificações e infraestruturas, muros, escadas, residências, barracas, restaurantes, ruas e estruturas de proteção, foram destruídos pela erosão costeira.

Quando perguntados sobre soluções para conter o avanço do mar, os entrevistados se dividiram entre construções de espigões, cuidados do meio ambiento e construção de muro de contenção e aterramento (Figura 8). Isto se dá pelo fato da maioria das obras de contenção a erosão costeira alterar a paisagem natural de uma praia, como observadas em algumas intervenções no Estado do Ceará, como por exemplo, espigões e muros de proteção.

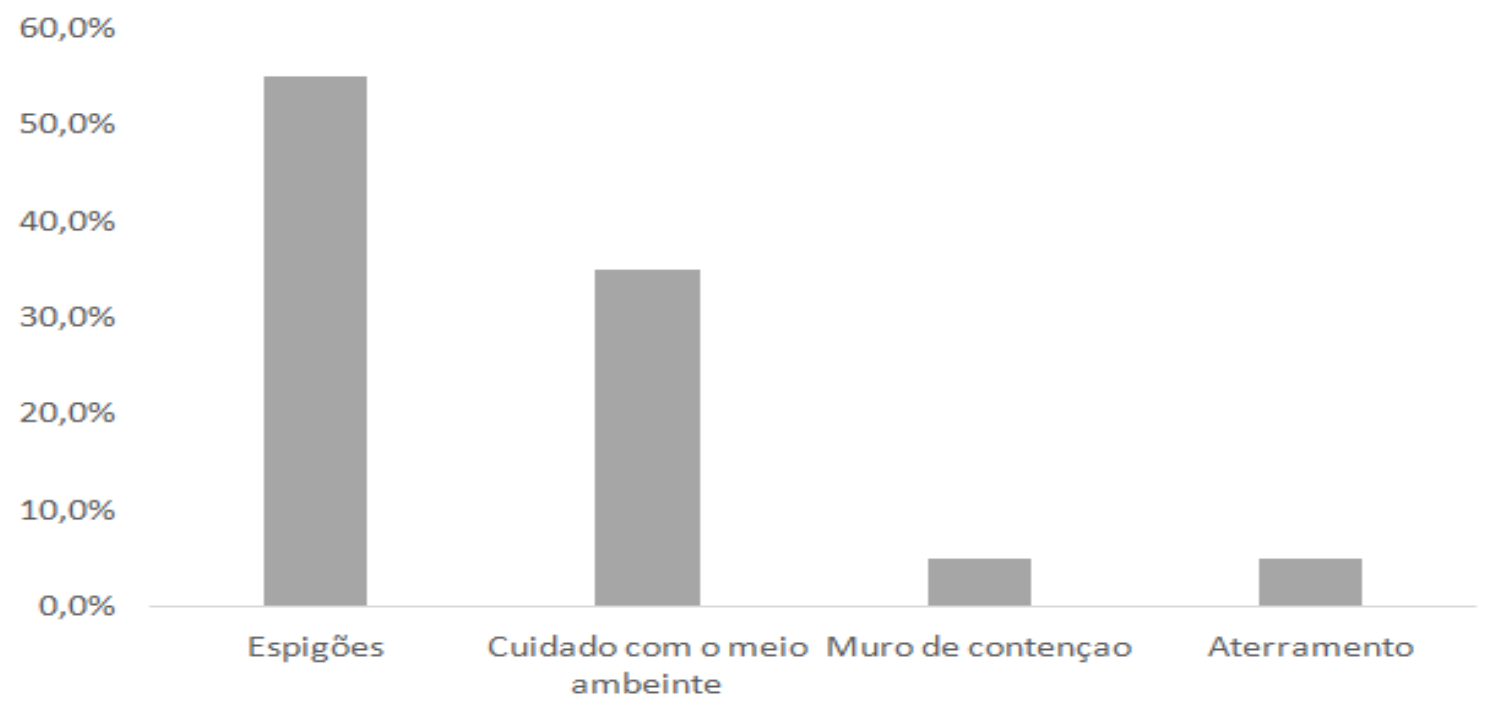

Figura 8. Medidas que impediriam o avanço do mar/erosão costeira na visão dos entrevistados.

Os entrevistados foram avaliados quanto aos seus graus de esclarecimento em relação às causas e consequências do avanço do mar/erosão costeira. Para isto, seis afirmativas foram apresentadas ao respondente para se posicionar concordando, 
discordando ou nenhum dos dois. As afirmativas dos respondentes são mostradas na Tabela 1, que demonstra o quão assertivo eles foram nas questões, sempre corroborando com a situação atual da praia.

Tabela 1. Concordância em relação às afirmativas sobre erosão costeira/avanço do mar na Praia do Icaraí, Caucaia-CE. D - discordo; NDNC - não concordo nem discordo; C - concordo.

\begin{tabular}{|c|l|c|c|c|}
\hline \multicolumn{2}{|l|}{ Item } & \multicolumn{3}{|c|}{ Opções } \\
\cline { 2 - 4 } 1 & $\begin{array}{l}\text { D avanço do mar é em grande parte causada por ações } \\
\text { humana. }\end{array}$ & - & - & $\begin{array}{c}\text { NDNC } \\
40 \\
(100 \%)\end{array}$ \\
\hline 2 & $\begin{array}{l}\text { O avanço do mar interfere nas atividades de lazer } \\
\text { turismo na praia. }\end{array}$ & - & - & $\begin{array}{c}40 \\
(100 \%)\end{array}$ \\
\hline 3 & $\begin{array}{l}\text { As obras contenção realizadas até agora foram } \\
\text { suficientes. }\end{array}$ & $\begin{array}{c}40 \\
(100 \%)\end{array}$ & - & - \\
\hline 4 & $\begin{array}{l}\text { As obras de contenção não prejudicam as paisagens da } \\
\text { praia. }\end{array}$ & $\begin{array}{c}40 \\
(100 \%)\end{array}$ & - & - \\
\hline 5 & $\begin{array}{l}\text { Prefiro perder a beleza cênica da praia e conter o } \\
\text { avanço do mar. }\end{array}$ & - & - & $\begin{array}{c}40 \\
(100 \%)\end{array}$ \\
\hline 6 & $\begin{array}{l}\text { Os órgãos públicos estão se preocupando com avanço } \\
\text { do mar. }\end{array}$ & $\begin{array}{c}40 \\
(100 \%)\end{array}$ & - \\
\hline
\end{tabular}

De acordo com a Tabela 1 observa-se que $100 \%$ dos entrevistados relataram que o avanço do mar é causado por ação humana. Outros estudos realizados no Canadá, na Nova Zelândia e na Malásia mostram que a erosão costeira está diretamente relacionada às modificações antropogênicas ocorridas nas respectivas regiões (Asmawi e Ibrahim, 2013).

No que tange ao lazer e turismo, todos os participantes concordam que o avanço do mar interfere no lazer e no turismo local. E que as obras de contenção realizada até agora não foram suficientes para solucionar o problema da comunidade e que estas obras de contenção prejudicam a passagem da praia. Este estudo mostra a semelhança com o estudo realizado por Medeiros et al. (2016) a respeito da percepção dos usuários em relação aos danos sofridos pelo turismo, observa-se que $85 \%$ da amostra concordam que a erosão costeira prejudica o turismo de uma praia.

Em relação ao avanço do mar, todos os entrevistados afirmaram que preferem perder a beleza cênica da praia, mas que ela seja preservada. Já em relação aos órgãos públicos, todos os entrevistados foram unânimes em afirmar que não há nenhum interesse por parte deste em solucionar os problemas causados pelo avanço do mar.

Sobre o grau de satisfação com as atividades de contenção realizados até o momento todos os entrevistados $(100 \%)$ relataram grau de satisfação muito baixo com os trabalhos realizados de contenção até o presente momento. Resultado diferente do encontrado por Medeiros et al. (2016), que ainda obtiveram algumas avaliações positivas em relação ao bagwall construído na Praia de Icaraí. Como esse estudo foi realizado três anos depois da implantação do bagwall, pôde-se notar a inviabilidade do mesmo, que se apresenta totalmente destruído após as ressacas marinhas (Figura 9). No entanto, os entrevistados estão receptivos e à espera de novas políticas públicas destinadas à melhoria da qualidade ambiental da Praia do Icaraí. 


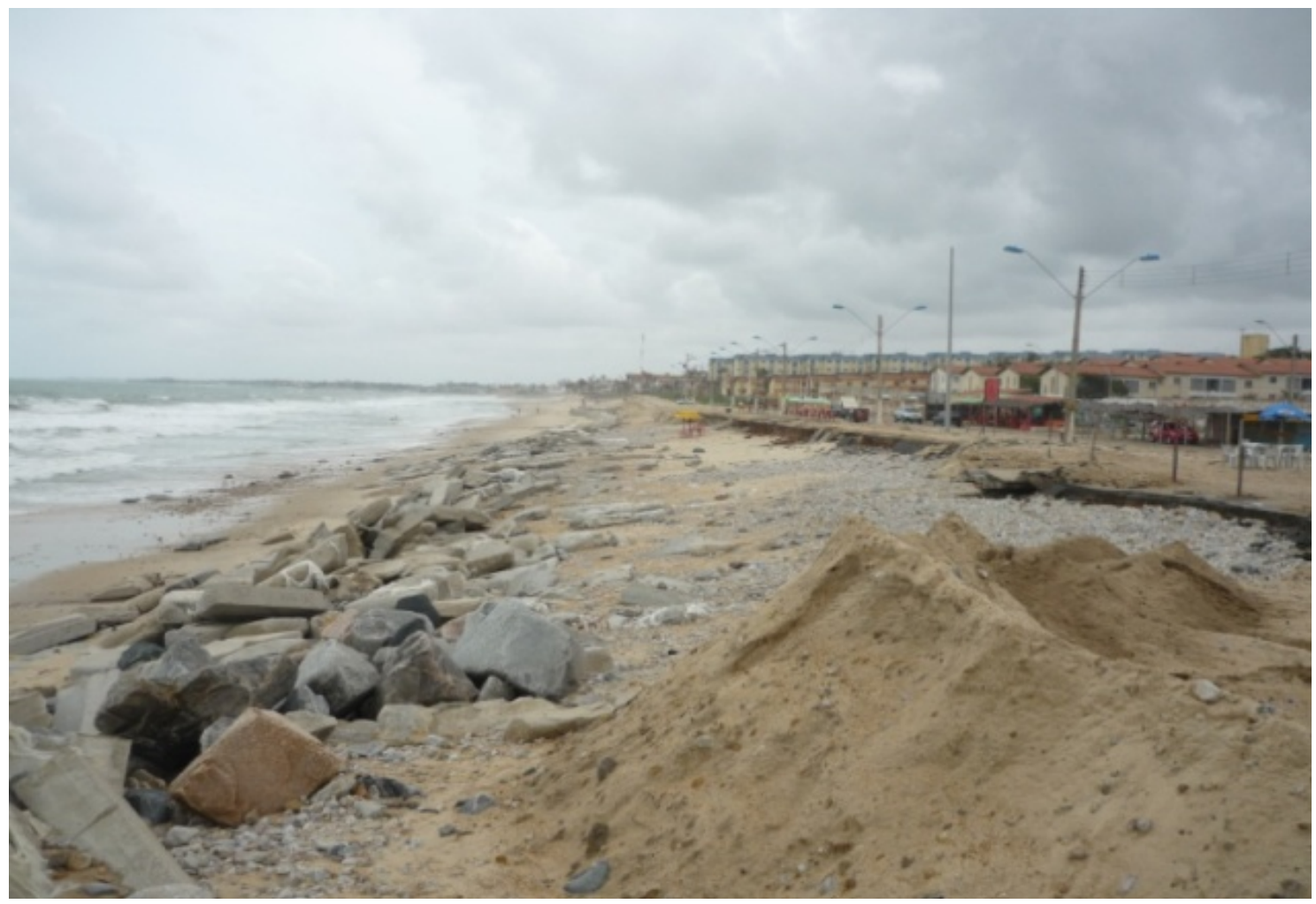

Figura 9. Bagwall destruído após ressacas marinhas.

De acordo com Souza (2011), houve uma rápida recuperação das dunas frontais na praia do Icaraí, onde ocorreu um acúmulo de mais de 120 mil metros cúbicos de areia, numa extensão de $1 \mathrm{~km}$ de praia após 6 meses de instalação do bagwall. As dificuldades envolvidas na implantação e recuperação de obras de proteção de áreas costeiras no Brasil, pois as barreiras para a solução efetiva da erosão estão associadas ao elevado custo econômico, normalmente à escassez de recursos municipais e ausência de políticas públicas.

Finalmente, para alguns aspectos analisados, a percepção socioambiental dos usuários da Praia do Icaraí está de acordo com os resultados de pesquisas realizadas em outras praias afetadas pela erosão costeira no Ceará, como Icapuí (Braga e Medeiros, 2015) e Cascavel (Brindeiro e Morais, 2018).

\section{Considerações finais}

As transformações sociais e ambientais que ocorrem na Praia do Icaraí em decorrência da erosão costeira e avanço do mar são sentidas pela população, que expressam suas visões de acordo com as experiências e identificação com a praia. Pode-se afirmar que o risco é percebido por toda a população entrevistada, pois os mesmos já vivenciaram momentos de ressaca do mar com prejuízos materiais.

No entanto, mesmo percebendo o risco, os resultados demonstram que maioria dos entrevistados prefere viver suscetível ao risco, pois possuem uma identidade com a praia, ou seja, têm uma sensação de pertencimento à comunidade, que foi construída com a trajetória de vida e tempo de utilização do lugar.

Os entrevistados deixaram claro a relação de culpabilidade das ações humanas em relação ao avanço do mar. Diante deste contexto, é relevante enfatizar que o homem, 
mesmo com as transformações ideológicas que ocorreram em alguns períodos da história, continua na atualidade a perceber a natureza apenas como fonte de matérias-primas quase sem valor econômico que alimenta a acumulação de capital em escala mundial.

É necessária a conjugação de mudanças culturais e transformações institucionais para estimular os cidadãos a participarem na produção de suas condições de existência e alterarem seus projetos de vida, de modo que possam preservar o meio ambiente para futuras gerações.

No que diz respeito às obras de minimização do risco do avanço do mar na comunidade, percebe-se que as mesmas são consideradas ineficientes, o que tende a intensificar o risco. Deste modo, deve-se formular políticas públicas direcionadas à valorização das áreas costeiras sempre levando em consideração o conhecimento e a expectativa da população local.

\section{Conflito de interesses}

Os autores declaram não haver conflito de interesses.

\section{Referências}

Asmawi M. Z.; Ibrahim A. N. The perception of community on coastal erosion issue in Selangor, Malaysia. Journal of Clean Energy Technologies, v. 1, n. 3, p. 164-168, 2013.

Braga, H.; Medeiros, W. D. A. Percepção do avanço do mar na praia da Barrinha, Icapuí/CE. Geotemas, v.5, n.1, p.49-62, 2015.

Brindeiro, F. O. C.; Morais, J. O. Percepção ambiental em relação ao avanço do mar na Praia do Balbino - Cascavel, Ceará, Brasil. Revista Meio Ambiente e Sustentabilidade, v. 14, n. 7, p. 1-12, 2018. https://doi.org/10.22292/mas.v14i7.817

Coriolano, L. N. M. T.; Silva, S. B. M. Turismo e Geografia: abordagens críticas. Fortaleza: Editora UECE, 2005.

Ergin, A.; Williams A. T.; Micaleff, A. Coastal scenery: Appreciation and evaluation. Journal of Coastal Research, v. 22, n. 4, p. 958-964, 2006. https://doi.org/10.2112/04-0351.1

Farias, E. G. G.; Maia, L. P. Uso de técnicas de geoprocessamento para a análise da evolução da linha de costa em ambientes litorâneos do Estado do Ceará, Brasil. Revista da Gestão Costeira Integrada, v. 10, n. 4, p. 521-544, 2010. https://doi.org/10.5894/rgci224

Fernandes, L. G.; Sansolo, D. G. Percepção ambiental dos moradores da Cidade de São Vicente sobre os resíduos sólidos na Praia do Gonzaguinha, SP, Brasil. Revista da Gestão Costeira Integrada, v. 13, n. 3, p. 379-389, 2013. https://doi.org/10.5894/rgci416

Gil, A.C. Métodos e técnicas de pesquisa social. São Paulo: Atlas, 2010.

IBGE - Instituto Brasileiro de Geografia e Estatística. Cidades. Rio de Janeiro: IBGE, 2014.

Lins-de-Barros, F. M.; Zeidan, F.; Lima, R. F. Adaptações e percepção da população a eventos de ressaca do mar no litoral de Maricá, Rio de Janeiro, Brasil. Revista de Gestão Costeira Integrada, v. 16, n. 2, p. 147-161, 2016. https://doi.org/10.5894/rgci591

MacLeod, M.; Silva, C. P.; Cooper, J. A. G. A comparative study of the perception and value of beaches in rural Ireland and Portugal: Implications for coastal zone management. Journal of Coastal Research, v. 18, n. 1, p. 14-24, 2002.

Marin, A. A. Pesquisa em educação ambiental e percepção ambiental. Pesquisa em Educação Ambiental, v. 3, n. 1, p. 203-222, 2008. https://doi.org/10.18675/2177580X.vol3.n1.p203-222 
Martins K. A.; Pereira, A. P. S.; Lino A. A.; Gonçalves, R. N. Determinação da erosão costeira no Estado de Pernambuco através de geoindicadores. Revista Brasileira de Geomorfologia, v. 17, n. 3, p. 533-546, 2016. https://doi.org/10.20502/rbg.v17i3.854

Medeiros, E. C. S.; Pantalena, A. F.; Miola, B.; Lima, R. S.; Soares, M. O. Percepção ambiental da erosão costeira em uma praia no litoral do nordeste do Brasil (Praia da Taíba, CE). Revista de Gestão Costeira Integrada, v. 14, $\quad$ n. 3, p. 471-482, 2014. https://doi.org/10.5894/rgci488

Medeiros, E. C. S.; Maia, L. P.; Araújo, R. C. P. Percepção ambiental do impacto da erosão costeira e da obra de contenção (bagwall) em uma praia no litoral do nordeste do Brasil. $\begin{array}{llllll}\text { Arquivos de Ciências do Mar, } & \text { v. 49, } & \text { n. 2, p. 57-67, }\end{array}$ https://doi.org/10.32360/acmar.v49i2.6581

Paula, D. P. Erosão costeira e estruturas de proteção no litoral da Região Metropolitana de Fortaleza (Ceará, Brasil): um contributo para artificialização do litoral. Revista Eletrônica do PRODEMA, v. 9, n. 1, p. 73-86, 2015.

Pinheiro, L. S.; Morais, J. O.; Oliveira, G. G.; Moura, M. R. Impactos da erosão nas atividades turísticas das Praias de Iparana e Pacheco. Caucaia-CE. Anais do II Congresso Brasileiro de Oceanografia - CBO, Vitória, 2005.

SETUR - Secretaria do Turismo do Estado do Ceará. Indicadores turísticos 1995-2012. Fortaleza: SETUR, 2012.

Souza, C. R. G. A erosão costeira e os desafios da gestão costeira no Brasil. Revista da Gestão Costeira Integrada, v. 9, n. 1, p. 17-37, 2009. https://doi.org/10.5894/rgci147

Souza, M. A. L. Recuperação de praias com o uso do dissipador de energia bagwall no litoral dos Estados de Alagoas e do Ceará, Brasil. Revista Gestão Costeira Integrada, v. 11, n. 4, p. 487-489, 2011. https://doi.org/10.5894/rgci302

Informação da Licença: Este é um artigo Open Access distribuído sob os termos da Licença Creative Commons Attribution, que permite uso irrestrito, distribuição e reprodução em qualquer meio, desde que a obra original seja devidamente citada. 